\section{Prevenção da AIDS entre os jovens: significados das práticas e os desafios à técnica}

\section{AIDS prevention among youths: meaning of practices and challenges to technique}

Katia Virginia de Oliveira Feliciano 1

1 Secretaria de Saúde de Pernambuco. Praça Oswaldo Cruz, s. n. Boa Vista. Recife, PE, Brasil. CEP: 50.000-000

\title{
Resumo
}

Estudo qualitativo, baseado na Teoria da Ação Comunicativa de Habermas, desenvolvido para investigar as sintonias elou tensões entre os discursos técnicos e práticos no campo da sexualidade e da prevenção da AIDS. O substrato empírico consistiuse de entrevistas individuais com 26 jovens de ambos os sexos, entre 15-20 anos de idade, estudantes de escolas públicas e privadas, moradores da Região Metropolitana do Recife. Os resultados mostram desacordos importantes entre os pressupostos $e$ lógicas argumentativas das duas modalidades de discursos, ressaltando a necessidade de uma atitude construtivista e interativa por parte dos profissionais de saúde na formulação de estratégias preventivas.

Palavras-chave Síndrome de Imunodeficiência Adquirida, Adolescente, Características culturais, Estudantes, Sexualidade 


\section{Introdução}

Um dos maiores obstáculos para o trabalho de prevenção junto à população jovem (ou a qualquer outro segmento populacional) é o predomínio da pretensão universalista das intervenções fundadas, exclusivamente, na transmissão de informações objetivas e persuasão racional, ou seja, a aspiração de generalização dos valores e interesses de preceitos técnicos e estratégicos, desconsiderando a capacidade das pessoas de fazer suas escolhas sustentadas pela própria compreensão das formas de vida que compartilham. ${ }^{1,2}$ Embora as ações de saúde articulem duas dimensões que são praticadas em conjunto, a técnico-científica e a relacional, o fato dessa relação acontecer entre pessoas que no plano social representam autoridades técnicas e científicas muito desiguais tem permitido justificar a assimetria para produzir, validar e expressar as competências e conhecimentos sobre a Síndrome de Imuno-deficiência Adquirida (AIDS).

Convém ressaltar que os atos regulativos correspondentes aos discursos institucionais, tais como, as instruções, as prescrições, as advertências e as recomendações veiculadas para a prevenção da AIDS, dão origem a "obrigações relevantes para a seqüência da interação", isto é, solicitam que os destinatários, além de concordarem com a linha de ação recomendada, passem a agir de acordo com as regras que ensinam a fazer bem o que se empreende. 3 Todavia, ao definir a priori as necessidades e as condutas a serem adotadas para atendêlas, a prática educativa focalizada no comportamento de risco limita a possibilidade de recorrer ao discurso argumentativo para produzir relações de entendimento sobre as responsabilidades que "deveríamos assumir" no que concerne à proteção contra o Human Imunodeficiency Vírus (HIV), recolocando criticamente os preceitos técnicos no contexto da vida das pessoas.

Essa pretensa separação entre o que é técnico e o que é valorativo, humano, presente nas ações de saúde, de acordo com Schraiber (1997: 129)4:

"[...] compromete a perspectiva de uma intervenção ao mesmo tempo eficaz e ética, assim como compromete a perspectiva de um domínio dos conhecimentos que esteja a serviço das necessidades dos homens e mulheres (sujeitos concretos) da e na vida social".

Com a linguagem sendo mais utilizada como um meio para a transmissão de informações indutoras do comportamento, colocando os profissionais na condição de dar e os jovens na de receber, a violência está dissimulada no ato do discurso. ${ }^{3}$ Isto é, a violência aparece por meio do impedimento da expressão das respostas advindas da experiência humana cotidiana vivenciada por cada recorte sociocultural que dá origem a subcategorias de indivíduos jovens, criando e recriando a pluralidade de juventudes.

Nos últimos anos, as críticas à limitada eficácia de intervenções comportamentais, focadas apenas no processo decisório racional, têm gradativamente deslocado as abordagens educativas para a valorização dos significados que orientam a prevenção da AIDS nos diferentes meios sociais, culturais e políticos.1,2,5 Essa perspectiva torna premente o reconhecimento de que os jovens, antes de querer e aceitar as orientações programáticas, com base nos padrões socioculturais onde se situam e na potencialidade crítica e autocrítica da reflexão, questionam a validade de recomendações sobre o uso do preservativo masculino e se interrogam "o que devo fazer?". Portanto, quando se defrontam com o exercício de julgar e decidir o que é e o que não é seguro e, de fato, pôr em ação a criatividade individual na transformação de suas práticas, eles buscam se reconhecer nas informações divulgadas, usando-as (ou não) para sua proteção.

Em todas as esferas da vida, as práticas são atividades cooperativas cujos sentidos são condicionados pelo sistema de convenções que atribui um sentido a cada gesto numa dada situação, ela mesma delimitada por esse sistema de convenções. 6 Na vivência da sexualidade e na prevenção da AIDS, portanto, é fundamental considerar os valores que estão enraizados no imaginário social e que são constitutivos das práticas de homens e mulheres. 1,5,7,8 Os significados que o gênero assume, na organização das experiências, fornecem uma referência importante por meio da qual o individuo adquire uma identidade que lhe permite situar-se no mundo social, aparecendo no trabalho incessante de interpretação das diferentes formas de viver a sexualidade (com parceiros do mesmo sexo, do sexo oposto, de ambos os sexos) e de lidar com suas conseqüências nãodesejadas. Assim cada pessoa procura adequar os distintos modelos de relação entre os sexos ao conjunto da sua vida e à diversidade das suas escolhas.

Conforme se elucidam as interações entre estrato social, gênero, idade, geração, raça e religião, os discursos reguladores que influenciam a possibilidade dos jovens explicitarem e submeterem a exame as razões potenciais para a tomada de uma posição, ${ }^{9}$ apresentam variações e contrastes que podem contribuir para o surgimento de outras necessidades 
no âmbito das decisões relacionadas à prevenção da AIDS (concretizar o desejo de ter filhos, demonstrar confiança no parceiro etc.). Essa diversificação na percepção de necessidades torna essencial considerar que: a) não existe uma perspectiva única, tampouco privilegiada, para formulação de juízos acerca de necessidades de saúde, já que esses juízos estão em contínua transformação e dependem das pessoas que os formulam; e b) as pessoas possuem interesses distintos, assim, as interações não estão isentas de conflitos e contradições. 10

A necessidade de usar o preservativo masculino faz da habilidade para negociar os conflitos interpessoais, resultantes do confronto de duas vontades, uma questão central para a diminuição da transmissão sexual do HIV. Apesar da complexidade das negociações no campo da sexualidade, o discurso técnico das instituições governamentais tem secundarizado a influência da construção social do gênero na negociação de práticas sexuais mais seguras que, por alguma razão, são de difícil aceitação por um dos parceiros. Não obstante a maior vulnerabilidade da mulher diante da disseminação do HIV o uso do preservativo masculino em última instância é uma decisão do homem - e tradicionalmente são eles que possuem múltiplas parcerias - não se pode conceber a assimetria de poder entre os gêneros de maneira estanque. Logo,

$$
\text { "[...] o que e como se negocia são }
$$
propensos a constantes contestações e reinvenções, de acordo com as relações $e$ contextos nos quais a mulher se encontra" (Barbosa; 1999: 79).11

São os conflitos do cotidiano que tornam a discussão prática indispensável, pois essa atua como fio condutor do emaranhado de discursos por meio dos quais as pessoas interagem e os modos de vida se organizam. O reconhecimento social da racionalidade científica para conceber e satisfazer as necessidades de saúde, ao destacar essencialmente o "sentido cognitivo" de conhecimentos e informações que fundamentam a eficácia das intervenções propostas para resistir ao crescimento da epidemia, parece obscurecer o fato de que as ações e os discursos são frutos de uma racionalidade processual, constituída por meio da linguagem, configurada nos múltiplos contextos de intersubjetividade contextos de relações sociais, econômicas, culturais e afetivas em que interagem tanto pessoas, como coletividades e instituições, em espaços e tempos determinados. Ou seja, desconsidera as implicações da prevenção com o "sentido prático" de alcançar o entendimento da melhor forma de agir.

Segundo a tipologia proposta por Habermas, 12 a ação humana pode ser: a) teleológica, na medida em que o agente calcula o meio mais eficiente para alcançar os fins desejados; essa ação é dada como instrumental, quando é orientada para a manipulação de objetos e estados de coisas, tornando-se estratégica, quando pretende exercer influência sobre a definição da situação ou a decisão do outro; b) normativa, quando pressupõe tacitamente um certo acordo socialmente integrante entre valores e normas; e c) comunicativa, na medida em que duas ou mais pessoas procuram chegar a um acordo voluntário por meio de um processo de interpretação cooperativo. Essas regras de ação regulam, simultaneamente, os contextos de interação, embora haja esferas das práticas e condições históricas em que predomine uma delas.

Tomando como referência o paradigma da comunicação que, focalizando-se numa razão centrada no entendimento intersubjetivo entre sujeitos capazes de falar e de agir, baseia-se em procedimentos argumentativos, a prevenção pode ser apreendida como a resultante de uma grande construção coletiva que envolve sujeitos diversos, portadores de diferentes projetos de mundo, em contínua e imprescindível interação material e simbólica. Nesse ponto é preciso considerar os dois tipos de comunicação distinguidos por Habermas 12: um consenso fático que sustentado pelo pano de fundo de lealdades, habilidades e padrões de interpretações consentidos, alimenta-se daquilo que sempre foi familiar; e um acordo verdadeiramente racional que depende da aceitação pelos interlocutores de pretensões de validez, as quais são contestáveis, mas são também defensáveis, mediante argumentos, portanto, discursivamente. No cotidiano, só quando há desacordo os significados e valores são objetos de discussão.

De acordo com este paradigma, na experiência crítica da AIDS, o discurso se realiza quando as pretensões de validade que estabelecem o consenso básico sobre as práticas propostas pelas instituições de saúde são questionadas. Em suma, quando os jovens apelam a um potencial de razões para esclarecer se essas práticas são: a) corretas: implementam ações legítimas para determinados contextos; b) verdadeiras: expressam certezas compartilháveis; e c) autênticas: estabelecem comunicação com diferentes experiências, inte-resses e afetos. As pretensões de validez são colocadas sempre no interior de determinados contextos, onde são aceitas ou rejeitadas. É a sua aceitação que cria os fatos sociais e os mantêm, mas essas pretensões podem ser desvalorizadas por meio de argumentos melhores e de processos de aprendizagem que transformam o contexto. Ou seja, as imagens de mundo e 
o tecido social no seu todo são perpassados por suposições de validade cujos conteúdos descritivos, valorativos e expressivos podem ser problematizados.

A argumentação desempenha um papel importante nos processos de aprendizagem, já que as relações que uma pessoa, ou um grupo social, estabelece entre a razão (faculdade de avaliar e emitir juízos) e o mundo, por meio das necessidades, dos interesses e da ação, continuam sempre contingentes se não são acrescidas da habilidade de aprender dos seus erros, da refutação de pressupostos e do insucesso das suas intervenções. A interdição dos procedimentos argumentativos cria obstáculos para o andamento das apreciações e decisões sobre a relação entre o que vale como conhecimento (discurso teórico) e a interpretação das necessidades à luz das informações existentes e das experiências vividas (discurso prático), 13 etapa essencial para o estabelecimento de um acordo por meio do qual as pessoas podem coordenar seus planos de ação e alcançar suas metas.

Para enfrentar o desafio, não estritamente técnico, da proteção contra o HIV, todos aqueles que estão comprometidos são instados a encontrar respostas para a pergunta: "Que objetivos queremos alcançar e por qual caminho?" Além do mais, como a educação em saúde é também uma ação interpessoal que põe em jogo os antagonismos de preferências e os conflitos de valores, evidenciando situações problemáticas provocadas por orientações individuais que não se conciliam, todos se defrontam com a necessidade de definir: "Quais são as regras da nossa convivência?". Por isso, neste trabalho, num contexto em que se prioriza a redução da prevalência do HIV entre jovens, são utilizadas as possibilidades abertas pela Teoria da Ação Comunicativa de Habermas ${ }^{12,13}$ para desenvolver uma hermenêutica da abordagem preventiva da AIDS nesse segmento populacional, com o intuito de contribuir para a reflexão crítica sobre a aplicabilidade prática dos discursos técnicos e das suas repercussões sobre as potencialidades do trabalho educativo.

\section{Métodos}

Nesta pesquisa, devido ao interesse de interrogar sobre o entrelaçamento e/ou tensão entre os argumentos técnicos e as sexualidades jovens visadas por esses argumentos, foram escolhidos jovens inseridos no sistema formal de educação porque teriam maiores oportunidades de acesso sistemático às informações sobre a prevenção da AIDS. É perti- nente lembrar que os seus resultados são parte do conjunto de resultados e conclusões produzidos pela diversidade dos modos como as vivências singulares se inscrevem na totalidade a que pertencem. A sua aplicação em contextos diferentes requer a mediação interpretativa, a qual, da perspectiva habermasiana, ${ }^{3}$ permite que pretensões de validez reconhecidas num dado contexto sejam criticáveis ou defensáveis noutros contextos. Ressalta-se, assim, a importância do papel seletivo dos contextos, isto é, da compreensão da sua especificidade.

Foram incluídas dez escolas (sete públicas e três privadas), localizadas na cidade do Recife, selecionadas pelo critério de conveniência: as primeiras escolas foram indicadas por professores conhecidos desta autora e, destas surgiram novas escolas, por meio da estratégia de rede de relações. $14 \mathrm{O}$ estudo cuidadoso das entrevistas permitiu a constituição de quatro conjuntos de discursos diferenciados em relação ao tipo de escolas:15 a) públicas que atendem a população que reside no seu entorno imediato (escolas locais); b) públicas que recebem a população de diferentes bairros e até mesmo de outras cidades da Região Metropolitana (escolas de referência); c) privadas para segmentos de menor poder aquisitivo; e d) privadas para segmentos de maior poder aquisitivo.

Em cada escola, os alunos foram indicados por professores e coordenadores devidamente esclarecidos sobre os objetivos do estudo. Entrevistaram-se 26 jovens, 13 homens e 13 mulheres, com idade entre 15 e 20 anos, estudantes do primeiro e segundo graus, moradores da região metropolitana do Recife. O número de entrevistados foi definido por "saturação",14 isto é, quando a pesquisadora obteve os elementos necessários para delinear o seu quadro interpretativo.

As entrevistas individuais semi-estruturadas foram feitas em salas fornecidas pelas escolas. Houve apenas uma recusa: uma estudante de escola privada para segmento de maior poder aquisitivo não compareceu ao encontro. Cada informante, encerrado o seu depoimento, recebeu os esclarecimentos necessários sobre a prevenção da AIDS.

$\mathrm{O}$ roteiro contemplou: identidade social, acesso a meios de comunicação, participação social, rede de interação imediata, concepções e vivência da sexualidade, doenças sexualmente transmissíveis e AIDS, fontes de informação. Utilizado como guia, foi percorrido respeitando a seqüência das questões relatadas pelo entrevistado, sendo explorados os pontos que permitiam aprofundar as informações fornecidas. Gravadas e transcritas, as entrevistas produziram 38 horas e 50 minutos de material. 
A duração de cada sessão dependeu do entrevistado e, em geral, foram necessárias duas sessões para obter todos os aspectos contemplados no roteiro.

Os discursos dos jovens foram interpretados em função dos três níveis de legitimação que, a partir da definição da comunicação como um diálogo, o sujeito falante interroga: a correção normativa, a verdade proposicional e a autenticidade expressiva. Assim, para conhecer "as condições de uso da linguagem", reconstruiu-se a rede simbólica de interação que reflete a aceitação intersubjetiva de pretensões de validez que legitimam as escolhas, esclarecendo os interesses e os sentidos dos discursos. Essa rede é formada pelas forças ilocucionárias que traduzem as intenções comunicativas dadas pelo falante ao conteúdo comunicado, indicando a função do enunciado em seu contexto de uso, ou seja, que a enunciação "conta como" constatação, comando, conselho, promessa etc. As condições de aceitação dessas pretensões derivam dos papéis dos falantes e do papel ilocucionário dos atos de fala "quê", "como" e em defesa "de quê" é colocado que norteiam as atitudes básicas (objetivante, de conformidade ou de crítica frente às normas e expressiva) seguidas na coordenação de ações. 12

Para responder à questão "fala-se o quê, quando se usa a linguagem", buscou-se identificar os pressupostos e os conceitos por meio dos quais são construídos a vivência da sexualidade, o conhecimento e as práticas preventivas. As principais categorias analíticas foram: a) gênero, como são elaboradas as diferenças sociais entre os sexos; b) necessidades, quais carecimentos precisam ser satisfeitos; e c) negociação, existência de discussão tendo em vista a obtenção de um pacto que viabilize a proteção frente ao HIV. Cada uma dessas categorias foi examinada através do percurso reflexivo e compreensivo da "dialética de pergunta e resposta" sugerida e possibilitada pela linguagem.

Para conhecer "o que estamos efetivamente fazendo ao falar" é preciso elucidar a aplicabilidade prática dos discursos técnicos sobre a prevenção da AIDS, conhecendo a sua aceitabilidade, isto é, as suas condições de "sucesso" (os jovens concordam com a ação recomendada?) e de "satisfação" (os jovens agem de acordo com as regras estabelecidas?). Habermas 12,13 considera que os níveis de significação dos atos de discurso contêm uma intencionalidade dual. No nível executivo, o discurso se caracteriza por uma atitude dirigida para uma relação intersubjetiva, com o falante explicitando sua intenção a um ouvinte; no nível da expressão, por um enunciado de conteúdo proposicional. É a compreensão do conteúdo e a aceitação da oferta feita pelo falante que traduz a produtividade do discurso.

Obteve-se aprovação do projeto pelo Comitê de Ética para Análise de Projetos de Pesquisa do Hospital das Clínicas e da Faculdade de Medicina da Universidade de São Paulo, de acordo com protocolo $\mathrm{n}^{\circ} 746$ de 11 de novembro de 2000, com a concordância da Secretaria de Educação de Pernambuco, da Secretaria de Educação do Recife e da direção das escolas. Os participantes foram esclarecidos acerca do caráter espontâneo da participação e do sigilo das informações, tendo sido solicitado o consentimento livre e esclarecido que no caso dos menores de 18 anos de idade foi assinado pelos seus responsáveis, respeitando-se os princípios éticos para pesquisa envolvendo seres humanos.

\section{Resultados e Discussão}

As implicações da pertença a um estrato social em relação à identidade de gênero e à atribuição de significados e a construção de espaços de ação para a vivência da sexualidade e proteção contra a AIDS tornam essencial traçar um rápido perfil dos participantes deste estudo. Os estudantes das escolas locais cursam o primeiro grau e têm inadequação de, em média, 4,7 anos entre a série que estão estudando e a que seria esperada para a idade. O núcleo familiar é constituído, principalmente, por mãe e filhos. É uma constante a efetuação de tarefas domésticas pelas moças e de biscate pelos rapazes. O estudo e o lazer acontecem dentro do bairro, com quase todos os componentes de suas redes de relações vivendo na mesma área e interagindo entre si.

Os alunos das escolas de referência estão no segundo grau e têm inadequação média de 1,5 ano entre a série que estão estudando e a que seria esperada para a idade. O núcleo familiar consta, sobretudo, de pai (ou padrasto), mães e filhos, mas há situações em que parentes são agregados. Em geral, os rapazes não trabalham e as moças ajudam em casa. O estudo e parte do lazer ocorrem fora do bairro de residência, com as redes de relações se estendendo para além das fronteiras da área local. Aqueles das escolas privadas cursam o segundo grau e, praticamente, não têm inadequação entre a série e a idade.Quase todos têm um núcleo familiar formado por pai, mãe e filhos. Os vínculos de amizade e o lazer, em especial nos segmentos de maior poder aquisitivo, mostram redes de sociabilidade onde são muitas as oportunidades para estabelecer novos relacionamentos com pessoas desconhecidas dos outros 
membros.

As práticas sexuais ou as expectativas em torno delas, em geral, estão centradas no coito genital com parceiro do sexo oposto. Nove rapazes e cinco moças já têm vida sexual ativa. A primeira vez é sempre uma experiência difícil, mas são diferentes as significações do difícil para o homem e a mulher. Como a identidade masculina é associada à "performance", as dificuldades para os rapazes estão relacionadas com a "competência no desempenho sexual", portanto, com o momento do ato. A iniciação é permeada pelos temores e, mesmo sem corres-ponder às expectativas, é considerada satisfatória porque permite principiar a aprendizagem e afirmar a identidade heterossexual junto ao grupo de pares. A primeira experiência, sem envolvimento afetivo (apenas uma foi com a namorada), ocorreu em torno dos 13 ou 14 anos, sendo comum o desconhecimento da "camisinha" e rara sua utilização sob a influência de parceira mais experiente.

As dificuldades das meninas, nos distintos meios socioculturais que continuam vinculando a vivência da sexualidade feminina à "preservação", voltam-se para as conseqüências do ato. Os relatos das moças são marcados pelos receios de reprovação, por parte dos familiares e amigos, e de desqualificação moral no contexto onde estão inseridas. Entretanto, em alguns grupos de pares, a inexperiência sexual já não representa um valor positivo. Entre aquelas que se iniciaram são habituais os sentimentos de culpa e arrependimento. As inquietações em relação ao momento do ato estão voltadas para a experiência do parceiro que deveria garantir a sua adequada realização. A iniciação sexual ocorreu ao redor dos 15 anos, com o namorado, todas tendo conhecimento da existência da "camisinha", embora tenha sido incomum o uso da mesma.

São diferentes, também, as trajetórias sexuais de moças e rapazes. As moças dizem que têm relações exclusivamente com os namorados. Não descartam a possibilidade da prática de sexo oral e relação anal com parceiro regular, com o qual tenham forte vínculo afetivo, mas enfatizam a falta de experiência com essas formas de prazer sexual. Não usam "camisinha" com freqüência porque mantêm um relacionamento fixo, conhecem as condições de saúde, confiam no parceiro, não pertencem a "grupos de risco" e pretendem engravidar como estratégia de continuidade da relação. A confiança no parceiro encerra um conflito, pois, em decorrência da diversidade admitida na vivência da sexualidade masculina, é grande a incerteza da fidelidade do homem. Justapõem-se os sentimentos de invulnerabilidade e suscetibilidade.
Os rapazes quando usam o condom, fazem-no de modo inconsistente, diferenciando as formas de proteção (e prazer) de acordo com os tipos de vínculos e os espaços da vida social; assim, nem sempre o que é considerado possível num dado relacionamento sexual, por exemplo, com uma menina com quem se está "ficando", pode ser possível noutro, por exemplo, com a namorada. Confiantes com relação às práticas preventivas adotadas, isto é, parceria fixa, seleção de parceiras eventuais (meninas conhecidas do bairro, escola e festas), uso da camisinha com parceiras eventuais promíscuas e, excepcionalmente, coito interrompido e sexo anal, julgam manter um distanciamento pessoal da AIDS que confina com a auto-exclusão. Os depoimentos atravessados pela incontinência do impulso sexual, a negação da suscetibilidade à infecção pelo HIV, a rejeição do preservativo pela parceira e a interferência do mesmo no prazer sugerem dificuldades para o uso regular.

Esses relatos mostram que os jovens são particularmente sensíveis aos discursos e práticas por meio dos quais as pessoas vão se construindo como homens e mulheres. Nesse sentido, os rapazes tiveram uma iniciação que Heilborn 16 qualifica como repentina: iniciação em que há separação entre sexo e sentimentos. Eles classificam as mulheres em categorias que definem "com quem se faz o quê" na vida sexual ativa, estabelecendo uma forte oposição entre a moça de família e a moça "fácil", "safada".1,5,7,8,16 Essa atitude ambivalente em relação à liberdade sexual feminina, certamente, reforça a lógica argumentativa que impregna as falas das meninas de que o amor e o afeto legitimam as práticas sexuais. Essas concepções têm desdobramentos importantes na prevenção da AIDS, criando a expectativa de que nos relacionamentos estáveis se pratica o sexo seguro.

Todos já ouviram falar da AIDS como sendo a única doença de transmissão sexual conhecida. A televisão, como outras fontes, 1,8,17 exerce um importante papel na divulgação: notícias, entrevistas e, principalmente, campanhas publicitárias dirigidas à sua prevenção. Afora os alunos das escolas locais, para os demais, os trabalhos e as palestras feitas nas escolas têm sido essenciais no aprendizado sobre a AIDS. O acesso ao material educativo institucional é mencionado, sobretudo nas escolas de referência e privadas para segmentos de menor poder aquisitivo. É pontual a participação de amigos, colegas, revistas, livros e filmes. Os estudantes das escolas locais estão menos informados sobre como não se contrai o HIV. Porém, é necessário considerar as formas diferenciadas de apropriação desses conheci- 
mentos e experiências no cotidiano dos jovens. 1,2,7,18

A noção de "grupos de risco" continua bastante arraigada na visão desses jovens, embora essa idéia já conviva com a percepção da vulnerabilidade de outros segmentos populacionais, sobretudo das mulheres, devido à possibilidade dos homens terem múltiplas parcerias com pessoas do sexo feminino ou de ambos os sexos. Essas concepções alimentam a compreensão de que, com a vida que levam, a chance de se infectar com o HIV estaria associada a um acontecimento acidental: rompimento do preservativo, infecção na transfusão sangüínea, no tratamento dentário e na coleta de sangue para exame. As mulheres, trazendo à tona a questão da fidelidade do parceiro, mostram-se mais propensas a admitir a própria suscetibilidade.

Como não querem ser apanhados desprevenidos, os meninos costumam trazer o condom na carteira ou no bolso. Porém, ambos os sexos deixam patente que não existe relação direta entre ter a "camisinha" na hora e utilizá-la, porque o sexo é quase sempre associado a situações inesperadas e não planejadas e/ou ocorre num relacionamento afetivo. As meninas, em particular, opinam que essa disponibilidade apareceria muito mais como um símbolo de virilidade e atividade sexual, interpretação semelhante àquela feita noutros contextos. 19 Contudo, nas redes de sociabilidade dos rapazes das escolas locais, nem sempre se confere uma valorização positiva ao preservativo masculino que pode, inclusive, comprometer a imagem de experiência e coragem associada ao "ser homem". Esses rapazes, também, expõem o conflito entre o desejo de ter filhos e a necessidade de evitar as doenças de transmissão sexual.

Quando adotam estratégias de proteção contra a transmissão sexual do HIV que são desautorizadas pelo conhecimento objetivo disponível e evidenciam o conflito entre o projeto de ter filhos e o discurso preventivo que define a necessidade de usar a "camisinha" em todas as relações sexuais, os jovens problematizam os preceitos programáticos que regulam a prevenção da AIDS. Isto é, eles não estão reconhecendo suas apreciações, sentimentos e desejos relativos à sexualidade nas prescrições e recomendações técnicas. Por isso, não é possível ajudá-los a identificar as opções mais aceitáveis para si próprios e para seus parceiros, dentre as práticas mais seguras para evitar a AIDS, sem pensar na compreensão dos significados e pressupostos que orientam as escolhas de um modo de vida autêntico. $1,2,5,7,8,20$

Quase sempre, o sexo seguro é associado à utilização do preservativo masculino. Todavia, as mulheres podem relacioná-lo à discrição quanto ao ato sexual, ao casamento que afiançaria relações monogâmicas estáveis e à prevenção da gravidez. Elas, principalmente, criticam a qualidade do material das "camisinhas", tidas como frágeis e fáceis de romper, questionando a sua eficácia na proteção contra o HIV; assim, desconsideram que a "falha da camisinha" decorre de não saber como usá-la. Nessa opinião, a validade das recomendações pragmáticas se mantém, mas ela já não está sendo considerada na ação. ${ }^{3}$ Ademais, é generalizada a visão de que o preservativo diminui o prazer do ato sexual e que na presença do afeto é muito mais difícil negociar o sexo seguro. Nesse contexto, a "quem" compete a responsabilidade pela proteção? A responsabilidade é repartida entre os parceiros? Quais esferas da ação como tomada de iniciativa para a negociação, garantia da disponibilidade do preservativo e sua colocação, competem a cada um? prepondera a concepção da responsabilidade mútua na tomada de iniciativa para negociar o uso da "camisinha", com o comprometimento dos dois parceiros revelando a preocupação com a necessidade de não vacilar, de se manter atento para superar uma possível resistência. Contudo, são diferenciadas as opiniões sobre a quem cabe trazer o preservativo masculino, garantindo sua disponibilidade no momento do ato. Aqueles que acham que pode ser tanto o homem como a mulher, focalizam toda a atenção na prevenção da AIDS e de outras doenças sexualmente transmissíveis. Já aqueles que acham que é o homem ressaltam a distribuição de tarefas e de poder entre os sexos, relacionando ou a experiência sexual à imagem de masculinidade, ou a necessidade de discrição à sexualidade feminina.

Entre os jovens das escolas públicas há quem atribua à mulher a responsabilidade de propor a utilização da "camisinha", argumentando que os homens não se preocupam com a prevenção e que as mulheres são mais vulneráveis às conseqüências das práticas sexuais. A responsabilização feminina na esfera da proteção contra a gravidez e as doenças provocadas pela atividade sexual, certamente, está relacionada à idéia de preservação, em nome da qual, desde muito cedo, as mulheres são ensinadas que é preciso cuidar de si, pois disso depende a sua respeitabilidade. Já a respeitabilidade do homem resulta da exposição: diversificação de parceiras, experiência, coragem e perigo. Esses discursos, entretanto, denotam a expectativa de que o homem fará prevalecer sua vontade. Diferente dos contraceptivos femininos passíveis de controle pelas mulheres, sem intermediação do parceiro, o uso do preservativo masculino depende da decisão do homem. 
A falta de hábito desses jovens para exercer o "poder em comum" se expressa na contradição entre a prática e o discurso que defende o compartilhamento da responsabilidade na prevenção da AIDS. Argumentando que já estão fazendo o melhor para os dois, a decisão dos rapazes com relação à utilização da "camisinha" é solitária. As moças dispõem de táticas para alcançar o que pretendem, mas essas apenas revelam que são maiores os obstáculos com que se defrontam na negociação do sexo seguro. 11,21,22 Nas poucas circunstâncias em que tentaram negociar, os parceiros só aceitaram colocar a "camisinha" quando a consumação do ato sexual foi condicionada à sua utilização. O engajamento do parceiro num modo de agir que não é de sua escolha ou preferência adiciona conflitos à vivência da sexualidade.

A construção de um pacto para adotar uma conduta protetora é um momento muito delicado que pressupõe, justamente, condições da pessoa, na sua vida sexual, de exercitar a independência da vontade com respeito mútuo. Entretanto, a racionalidade estratégica dos preceitos técnicos, ao prescindir do convencimento recíproco sobre a correção dos argumentos apresentados, limita a responsabilidade do sujeito à capacidade de decidir sobre o uso do preservativo e controlar algumas das condições necessárias para alcançar seus intentos. Ou seja, amplia sua autonomia, aumentando as possibilidades daqueles que detêm maiores poderes recorrerem à coerção na negociação dos conflitos interpessoais. ${ }^{3}$ Cabe chamar a atenção que, nesse caso, a idéia de autonomia está ligada à do "constrangimento", na medida em que alude a um sujeito autônomo, seguro de si, gestor de suas relações e necessidades, capaz de fazer valer sua vontade.

Nos discursos desses jovens sobre a sua sexualidade e a prevenção da AIDS, as diferenças atribuídas e vividas pelos dois sexos são evidenciadas nas: a) visões de mundo que dificultam a percepção da vulnerabilidade ao HIV e a apropriação das informações sobre como se proteger; b) limitações da comunicação entre parceiros; c) indefinições relacionadas à repartição das responsabilidades nas práticas preventivas; e d) dificuldades para assegurar o uso consistente do preservativo masculino. $\mathrm{O}$ fortalecimento da capacidade de desfrutar a sexualidade de modo saudável, sem discriminação de gênero, relaciona-se com interações e circunstâncias socialmente complexas, e não apenas com o livre arbítrio do sujeito. Logo, subentende a transformação das concepções mais tradicionais de masculinidade e feminilidade, dos pontos de vista individual, coletivo e institucional.11,21-23

\section{Considerações finais}

As interrogações, reflexões e conflitos motivados pelas práticas relacionadas com a vivência da sexualidade e a proteção contra o HIV reiteram que a prevenção depende de um processo de diálogo que obtenha, por meio da aceitação intersubjetiva das pretensões de validez dos diversos discursos "circulantes", o consenso de que as práticas propostas são adequadas, funcionam e são do autêntico interesse das pessoas. O grande desafio no campo da educação em saúde é entrar em contato efetivo com as aspirações dos jovens, sem perder de vista o compromisso do profissional com o adequado enfrentamento, em termos individuais e coletivos, da epidemia de AIDS. A tarefa é combinar intervenção com acolhimento, isto é, ser propositiva, mas reconhecendo a presença do outro no trajeto até a efetuação das estratégias de prevenção.

No âmbito da aplicação de programas de saúde, cabe compreender o deslocamento que essa perspectiva da ação humana provoca na posição dos participantes. O jovem deixa de ser "todo aquele" que, no sentido de qualquer um, recebe as orientações preventivas, para ser o "cada um" que, no sentido da sua singularidade, é portador de direito, condicionando a necessidade de arbitrar entre reivindicações concorrentes. 6 A necessidade de arbitragem coloca em questão a opção por um dos tipos de solução de conflitos e de formação coletiva da vontade: a) a prática de "entendimento" que visa a obtenção de um "consenso" racionalmente construído; e b) a prática de "negociação" que se propõe à formação de "um pacto". 3

Diante de demandas provocadas por interesses conflitantes, a negociação exige a disposição cooperativa para estabelecer compromissos. Para evitar que a assimetria de poder e os potenciais de ameaça prejudiquem seu êxito, a negociação recorre a procedimentos destinados a garantir a eqüidade dos possíveis compromissos. Esses procedimentos regulam o direito à participação, o tipo de temas e contribuições, a permissão de sanções etc., fazendo que a negociação seja considerada como uma "combinação" entre as partes, já que assegura chances iguais de participação a todos os interesses conflitantes. Na combinação, o pacto é alcançado de modo não-coercitivo, mas não traduz uma "maneira de ver" comum, podendo ser aceito por razões "diferentes": considerações racionais de vantagens e desvantagens, hábito arraigado e reconhecimento da autoridade do profissional de saúde. Portanto, difere do entendimento no qual os participantes questionam as pretensões de validez criticáveis, a fim de alcan- 
çar o "convencimento" recíproco da correção de seus argumentos.

É preciso atentar que nos processos de negociação os significados e valores que as pessoas atribuem às práticas preventivas são reduzidos a simples questões estratégicas. Por esse caminho, a interpretação das necessidades, a oposição de interesses e a escolha de um modo de vida autêntico, aspectos fundamentais para as definições relacionadas com a prevenção da AIDS, são secundarizadas pelos problemas de informação e escolha racional de meios. As negociações, ainda quando eqüitativas, acabam subestimando a distância entre as suposições de validade institucionais e as formas de proteção adotadas pelos jovens, o que diminui a sua capacidade para ajudá-los a se protegerem consistentemente do HIV.

$\mathrm{Na}$ perspectiva de sua intenção comunicativa, o uso da linguagem busca necessariamente alcançar o entendimento, no sentido de um processo de interpretação cooperativo. O agir comunicativo distingue-se do estratégico, uma vez que a coordenação bem sucedida da ação não está apoiada numa racionalidade orientada para um fim, mas numa racionalidade que se manifesta nas condições requeridas para o entendimento motivador da convicção. Para Habermas (1997: 386): 13

"Não significa que os sujeitos que atuam comunicativamente não possam se orientar, também, pelo próprio êxito; mas no âmbito da ação comunicativa só podem alcançar o êxito que buscam, através da obtenção de um entendimento; o entendimento é determinante para a coordenação de suas ações".

É o princípio da democracia que faz supor a possibilidade de olhar criticamente as propostas de ação e de buscar o entendimento sobre pretensões de validade problemáticas, por meio do movimento livre de temas e contribuições, informações e argumentos. A liberdade comunicativa é que assegura a legitimidade das intervenções, conforme abre espaço para a concretização da congruência entre a autonomia do julgamento de cada um e a expectativa do consenso de todas as pessoas que dizem respeito à discussão prática. ${ }^{3}$ Torna-se, portanto, essencial criar condições para a formação e renovação de uma "vontade comum" pelos membros de uma comunidade. 6

A construção do entendimento é uma forma de comunicação que pressupõe a possibilidade de neutralizar as relações de poder e solicita a mediação institucional para definir um ponto de equilíbrio entre extremos marcados pelas desigualdades entre o dar e o receber. A chave para responder a essa questão seria abrir espaço para cada uma das contribuições necessárias ao enfrentamento do problema. Ou seja, admitir que na relação entre as instituições de saúde, com o seu conhecimento científico, e os jovens, com a sua compreensão da adequação ou inadequação de valores a circunstâncias específicas, não existe um que não sabe, mas dois que sabem coisas distintas.

Esse procedimento tem implicações importantes na relação entre a instituição e os jovens, pois se os profissionais de saúde renunciassem à sua posição de detentores privilegiados do saber, poderiam participar mais ativamente do ir-e-vir discursivo entre a explicação teórica e a justificação prática. Isto é, assumiriam uma postura construtivista e interativa na formulação de estratégias preventivas. Como as mudanças na vivência da sexualidade que permitem às pessoas se protegerem do HIV são fruto de um trabalho de longa duração, os jovens necessitam beneficiar-se de um processo educativo empenhado na construção de uma vida consciente e assumida criticamente. 1,5,7,20 Nesse sentido, o interesse fundamental é a reconstrução das condições existentes, nos distintos contextos, para que usufruam sua sexualidade por meio de práticas saudáveis e solidárias.

\section{Agradecimentos}

Ao Prof. Dr. José Ricardo de C.M. Ayres, pela orientação. 


\section{Referências}

1. Paiva V. Fazendo arte com a camisinha. São Paulo: Summus; 2000.

2. Parker RG. Na contramão da AIDS: sexualidade, intervenção, política. Rio de Janeiro: ABIA; 2000.

3. Habermas J. Direito e democracia: entre facticidade e validade. Rio de Janeiro: Tempo Brasileiro; 1997. v. 1

4. Schraiber LB. No encontro da técnica com a ética: o exercício de julgar e decidir no cotidiano do trabalho em medicina. Interface: Comun Saúde Educ 1997; 1: 123-38.

5. Paiva V, Perez C, Blessa C. Jovens e adolescentes em tempo de AIDS: reflexões sobre uma década de trabalho de prevenção. Psicologia (USP) 2002; 13: 55-78.

6. Ricoeur P. O si-mesmo como um outro. Campinas: Papirus; 1991.

7. Paiva V. Sexualidades adolescentes: escolaridade, gênero e o sujeito sexual. In: Parker R, Barbosa RM, organizadores. Sexualidades brasileiras. Rio de Janeiro: Relume Dumará, 1996. p. 213-34

8. Monteiro S. Gênero, sexualidade e juventude numa favela carioca. In: Barbosa RM, Parker R, organizadores. Sexualidades pelo avesso: direitos, identidades e poder. Rio de Janeiro: Instituto de Medicina Social da Universidade Estadual do Rio de Janeiro; 1999. p. 117-45.

9. Louro GL. Gênero, sexualidade e educação: uma perspectiva pós-estruturalista. 3. ed. Petrópolis: Vozes: 1999.

10. Ayres JRCM, França Jr I. Saúde do adolescente. In: Schraiber LB, Mendes-Gonçalves RB, Nemes MIB, organizadores. Saúde do adulto, programas e ações na unidade básica. São Paulo: Hucitec; 1996. p. 66-85.

11. Barbosa RM. Negociação sexual ou sexo negociado? Poder, gênero e sexualidade em tempos de AIDS. In: Barbosa RM, Parker R, organizadores. Sexualidades pelo avesso: direitos, identidades e poder. Rio de Janeiro: Instituto de Medicina Social da Universidade Estadual do Rio de Janeiro; 1999. p.73-88.

12. Habermas J. Teoria de la acción comunicativa. 2. ed. Madrid: Taurus; 1988

13. Habermas J. Teoría de la acción comunicativa: complementos y estudios previos. 3. ed. Madrid: Ed. Cátedra; 1997.
14. Schraiber LB. Pesquisa qualitativa em saúde: reflexões metodológicas do relato oral e produção de narrativas em estudo sobre a profissão médica. Rev Saúde Pública 1995; 29: 63-74.

15. Minayo MCS. Fase de análise ou tratamento do material. In: Minayo MCS. O desafio do conhecimento: pesquisa qualitativa em saúde. 2. ed. São Paulo: Hucitec; 1993. p. 197-247.

16. Heilborn ML. Construção de si, gênero e sexualidade. In: Heilborn ML, organizadora. Sexualidade: o olhar das ciências sociais. Rio de Janeiro: Zahar; 1999. p. 40-58.

17. Loyola MA. AIDS e prevenção da AIDS no Rio de Janeiro. In: Loyola MA, organizadora. AIDS e sexualidade: o ponto de vista das ciências humanas. Rio de Janeiro: RelumeDumará; 1994. p. 19-72.

18. Pitta AMR. Interrogando os campos da saúde e da comunicação: notas para o debate. In: Pitta AMR, organizadora. Saúde \& comunicação: visibilidades e silêncios. São Paulo: Hucitec; 1995. p. 239-66.

19. Mota MP. Prevenção entre adolescentes de baixa renda: desafios e possibilidades. Bol ABIA [Associação Brasileira Interdisciplinar AIDS] 1998; (42): 4-6.

20. Ayres JRCM. Cidadania, vulnerabilidade e prevenção de HIV/AIDS. In: Pinto T, Telles IS, organizadora. AIDS e escola: reflexões e propostas do EDUCAIDS. São Paulo: Cortez; 2000. p. 21-8.

21. Villela WV. Refletindo sobre a negociação sexual como estratégia de prevenção da AIDS entre as mulheres. In: Parker R, Galvão J, organizadores. Quebrando o silêncio: mulheres e AIDS no Brasil. Rio de Janeiro: RelumeDumará; 1996. p. 181-9.

22. Villela WV. Prevenção do HIV/AIDS, gênero e sexualidade: um desafio para os serviços de saúde. In: Barbosa RM, Parker R, organizadores. Sexualidades pelo avesso: direitos, identidades e poder. Rio de Janeiro: Instituto de Medicina Social da Universidade Estadual do Rio de Janeiro; 1999. p. 199-213.

23. Garcia SM. Conhecer os homens a partir do gênero e para alem do gênero. In: Arilha M, Ridenti SGU, Medrado B, organizadores. Homens e masculinidades: outras palavras. São Paulo: ECOS; 1998. p. 31-50.

Recebido em 21 de dezembro de 2004

Versão final em 13 de maio de 2005

Aprovado em 3 de agosto de 2005 